\title{
Social Media and the Question of Truth: A Sociological Study of Fake News in India in Pandemic Times
}

\author{
Bose Adrija, Jha Ganga Nath and Behera, Haricharan ${ }^{1}$
}

\begin{abstract}
One of the widely discussed issues regarding social media today is the fake news. With the Covid19 crisis forcing people to stay indoors, social media emerged as a platform for information database for politicians, policy makers, health practitioners and citizens alike. Recent evidences show there has been rampant spread of news which are unverified and spurious concerning public health, leading to severe social-political debates. The main objective is to see the linkages between fake news and social behavior on social media and its sociological consequences. The aim of my paper is to look at the question of fake news in the wake of the Coronavirus crisis in consideration to how it is being used to spread alternative facts, majority of which are unverified. My research question is- have we reached a time where alternative facts are existing in the information environment and whether it impacts the socio-political dynamics in our country. This paper will try to uncover the patterns of fake news, majorly the relationship between social media, truth and social behavior. Methodologically I will try to look into why people believe and share unverified information. This will help me conclude whether the country is heading towards a post-truth era.
\end{abstract}

Keywords: Coronavirus, Social Media, Fake News, Post-Truth, Social Behavior, India, Alternative Facts.

${ }^{1}$ Adrija Bose is a Senior Research Fellow, Sociological Research Unit, Indian Statistical Institute, India; Ganga Nath Jha is Assistant Professor, University Department of Anthropology, Vinoba Bhave University, India; and, Haricharan Behera is Assistant Professor, Sociological Research Unit, Indian Statistical Institute, India 


\section{Introduction}

With the pandemic growing worldwide, what took place was not only people and medical institutions dealing with the virus but also combating a wave of misinformation. As there was a situation of lockdown and knowledge about the virus completely unknown, people turned to social media for extracting information about it and possible symptoms and remedies. Contrary to what was expected as to social media providing authentic and valid information, what was visible was the sudden wave of fake news and doctored truth inundating the sites and these being shared across the platforms in large numbers. From supposed medications circulating as home remedies and dietary restrictions to racial stereotypes and discriminations against the minority, India was suddenly in the headline for her huge wave of unchecked information circulating. World Health Organization and other institutions termed it as battling an 'infodemic's as it posed not only a problem for finding out a solution for the disease, but it also hid truths and facts- again which was articulated to have power politics behind it. The result was fake news becoming similar to an actual virus to be combated and people across the country taking a pile of unverified and unchecked information to be the actual truth and adopting them in real life. In India it presented a unique picture as the high rate of illiteracy and awareness coupled with higher penetration of smartphone made it easier for fake news to spread easier and faster. The Government of India's circular ${ }^{3}$ in regard to curbing fake news points out the trend in media sharing unverified information and false claims in a bid to create panic directs us to the fact that how fake news has become a social problem which needs to be combatted fast.

Social media and internet has become a reality of our cultural and communication sphere in recent times (Shirky, 2011), therefore expanding the public sphere, inviting a large number of people to share their opinion and build a wider social network initiating conversation, debate and dialogue. The technological revolution which was accompanied by an expansion of smartphone and mobile

\footnotetext{
${ }^{2}$ According to World Health Organization (WHO), an infodemic is the result of sudden surge of information, generally false or misleading shared in both digital and physical environments during an emergency such as war or disease. See https://www.who.int/health-topics/infodemic\#tab=tab_1

${ }^{3}$ See https://www.meity.gov.in/writereaddata/files/advisory_to_curb_false_newsmisinformation_on_corona_virus.pdf
} 
technology brought the world of internet and social networking platform at our fingertips. This was a major paradigm shift in the sphere of media and communication where information and news were shared constantly, unrestricted and in large amount. With the emergence of social media, the kind of information being circulated in the different social networking sites and their authenticity has always been a cause of concern and with the increasing spread of fake news, this apprehension has increased manifold. Unfiltered news, misinformation or hoax stories to create unrest or subjugate a group of people deliberately have questioned the relevance of social media as a platform for free discussion and interaction. India has registered a growth in high-speed internet with a drastic increase in the number of first time users ${ }^{4}$. Although the market of internet devices is expanding and an equal surge in the availability of information, there has been no consequent growth in media literacy. As a result there is a lack in understanding and differentiating the real information from the fake one. Consuming social media information is similar to using a "double aged sword". Firstly, it is fast and profitable, so it helps in reaching larger numbers of people within a short time. But the information which is consumed may be a fake and unverified one. Thus, those who are willingly sharing fake news to share propaganda, social media is an easy tool to serve the purpose. Moreover the rapid spread of fake news carries the possibility to negatively impact the individual and the society as a whole. The outbreak of Covid-19 virus can be cited as one of the prime examples when different conspiracy theories, untested medicines and cures and fake claims and news regarding the virus were heavily circulated in various social media platforms. This was termed as 'infodemic' by the World Health Organization (WHO) which depicted a sudden spurt in the amount of information and misinformation without any authentic source which makes it hard for people accessing them to believe which is verified and which is not. Various social media accounts and micro-blogging platforms were reported to have allowed numbers of myths and rumors which had the potentiality to harm public health. The severity of such fake news led WHO to call the nations to counter such misinformation, which was followed by different governments framing policies and framework to curb the unwarranted spread of unchecked information through the digital platforms. Media scholars and researchers have reflected upon this move by the Governments as a scope to restrict and prohibit freedom of

\footnotetext{
${ }^{4}$ India registered 504 million active internet users in 2019. For more information check https://cms.iamai.in/Content/ResearchPapers/2286f4d7-424f-4bde-be88-6415fe5021d5.pdf
} 
expression in future. Massive growth in fake news and its effect on democracy and social fabric has expanded the interest on how to detect fake news and the actors who take part in it, both on the production and consuming level and the psychology behind it. This paper will thus focus on the social behavior that enables one to indulge in believing and sharing fake news in order to explore the possibilities whether the future of the information society is a post-truth world marked by alternative facts.

\section{The spread of fake news}

The word 'fake news' became popular since 2016 (Ball, 2017) when it was deliberately used for political gains. Since then social media has been rife with fake news and misinformation being spread by different pages on the networking platforms, in many instances anonymous profiles spreading misleading information. The EU High Level Expert Group talked about "disinformation" which in a broader sense refers to all kinds of false, inaccurate and misleading information mainly designed and promoted to cause public harm intentionally for making profit. The Collins Dictionary defines fake news as a provocative false information which is spread and circulated in the names of news contents. It is a forged piece of information which imitates contents of actual news reporting but not with any organizational purpose (Bharali, 2010). However, this exercise of fabricating information and spreading them is not new. In this context, a number of media scholars have pointed out that spreading misinformation and propaganda is an age old phenomena (Fondren, 2019); the process has been hastened by technology which disseminates it fast and effectively. The recent spurt of fake news has been majorly driven by social media, characterised by a significant shift from mass media and yellow journalism to the digital media and operated in a disorganized fashion (since social media is an automated media with users creating contents in large numbers whenever and wherever possible) and with the impact on sociality being deeper.

In the wake of Covid-19 when the healthcare and administrative systems around the globe are in a disarray, the issue of fake news has gained a new momentum majorly due to the lack of vigilance and an equal lack of knowledge. Moreover the spread of fake news at such a high pace through social media shows a lack of legal controlling measures in spreading fake news and lies. With a general lack of knowledge about the virus and its details, the random fake news transgressed into 
hate speeches and violence ${ }^{5}$. The recent headways in this area have come up with newer techniques which intends to detect the source of fake news. One important point to consider is that there is a variation in the type of fake news that is spread amidst the pandemic, which also throws light on the role of social media in information dissemination during pandemic. The first category of fake news are the misinformation with no deliberate intention to spread hate or harm, but they are simply unverified and arise from the human desire to fetch more evidence regarding a phenomenon that doesn't have sufficient information. Naturally these awakens curiosity in human mind and thus the tendency to believe any facts and circulate them within known and close ones arise. Social media platforms circulated information which included rumours about the spread of the diseases from a certain place, fake claims about the treatment of the virus, or certain seasons will weaken the virus and other assumptions. Another kind of fake news is the intended spread of disinformation. Here wrong information is spread purposely- either to intentionally cause harm to other party or for personal profits. Instances like accusing a certain community of people for spreading the virus or hiding the actual numbers of affected or wrong information about vaccination were some of the most highlighted fake news issues in India discussed by the governments and media scholars. Additionally rumours were spread regarding movements of citizens such as people coming from abroad are carrying the virus into the country. This not only violated the individual privacy but also spread fear in the minds of the people. Thus there is a necessity to study people's perspective on fake news and ways to control it is an important area of discussion. What this paper intends to see is who are the actors behind the spread of such misinformation with an insight into their social behaviour.

There has been speculations from various corners of the society that fake news and "infodemic" are spreading faster than the virus in the country. With the virus striking the country, social media platforms were inundated with fake posts and rumours about the virus, conspiracy theories about its nature and origin and subsequent unverified remedies. Platforms such as Facebook, Twitter, WhatsApp and the recently banned TikTok were flooded with people sharing fake images and

\footnotetext{
${ }^{5}$ Fake news becoming a menace amidst the pandemic in India. See https://www.orfonline.org/expert-speak/howfake-news-complicating-india-war-against-covid19-66052/
} 
interview clips. It was reported that Covid-19 related fake news spiked in the month of April ${ }^{6}$, particularly after the Tablighi Jammat in Delhi (Sharma, 2020). Fact checking websites across the country revealed that $35 \%$ of the videos circulated were fake, $29 \%$ false images ${ }^{7}$ and other range of issues such as incorrect diagnosis and spurious treatment along with dubious guidelines. Worrisome, a good chunk of these malformation were directed towards the minority groups accusing them as the carrier of the virus which further complicated the fight against the virus.

\section{Interpreting fake news}

Growing literatures on fake news emphasized on the impact it has on society and how they pose a difficulty for audiences to distinguish between real and fake news content and thus manipulating the individual. The most pertinent question which still has remained unanswered what factors enable consumers to share fake news online. In the context of Covid-19, a fake news amidst emergency can induce fear and panic in the society. As a consequence to this, different control measures implemented by the Governments can become ineffective for a certain period of time as damage control becomes the main purpose during that time. So in case of spreading fake news and propaganda, timing plays an important factor which automatically directs to the question whether there is some intent behind sharing the fake news. Not only the issues of fake news but its content has become a topic of global debate like the cure through unverified medicines and the spread of virus due to consumption of certain food. Although the Governments have made it clear that so far any homemade cure have been found to be tackle the spread of the virus fast, still there have been no curb in the amount of fake news being shared. One of the reasons why fake news is thriving is in the covid crisis is that the frequency of using social media has drastically risen in this timeframe as there is a restricted imposed on physical movement and social gatherings. Besides exchanging general information, social media are also used by citizens during an emergency to find relevant facts and take part in organized cooperative actions if possible. In all of these activities on social media for pandemic response, an issue regarding the integrity of what is posted rises. There may be information that users may post or share believing them to be true and in some cases with the

\footnotetext{
${ }^{6}$ Maximum fake news were reported in April in India. See https://indianexpress.com/article/india/fake-news-in-thetime-of-coronavirus-boom-analyses-178-fact-checks-on-covid-19-related-misinformation-since-january-6401441/

${ }^{7}$ See https://newssense.in/2020/05/10/fake-news-in-the-time-of-coronavirus-a-study-by-boom/
} 
deliberate intention to spread misinformation and create panic. Literatures on fake news also include a concept called "echo chambers" which accelerates the spread of misinformation over the platform. It is referred to a homogenous social space that emphasises and highlights certain views and beliefs within a network that works as an ideology and censors opposite perspectives coming from a different and credible source. These two amplifies the creation of misinformed knowledge and thus affecting the decision making process. Although factors like the design of social media and the algorithms have helped in the formation of echo chambers, there are evidences which show that biased human cognition and beliefs have resulted in people reinforcing the fake news. On another note, not only regular social media users but also the States spread propaganda due to political and strategic intentions (Posetti, 2017). For example a number of countries including India has been seen to misreport the numbers of affected and deaths due to the virus in order to depict their achievements in battling the virus. States spread fake news and falsehood for a number of reasons, like preventing any criticism from its subjects, to divert attention from the actual issue to something which is insubstantial or to change the narratives. Added to this there are several antiestablishment groups who distorts information in order to impose their narratives. These includes conspiracy theorists who spread misinformation against wearing gloves or sanitizing hands, to groups condemning the vaccines as outrageous and blasphemous thus undermining the importance of medical practitioners and political bodies.

Media and communication scholars have been studying the typologies of fake news, especially what can be some of the substantial reasons behind their productions and circulations and the consequences. A sociological perspective to this points out that the main motive behind producing fake news are mainly commercial and political interests. Those news which are created with the sole aim to increase the viewership of a site and get more revenues through sharing that particular content is regarded as a commercially motivating factor. On the other hand, there are ideological factors and political interests too. These categories of fake news are based on manipulating tactics, offending any figure from the opposition and their image through spreading spurious information. The main agenda here is to impose their own ideology or favour someone belonging to the same school of thoughts. Since social media sites in India have become unrestricted and free platforms for news sharing and consumption, the impact of fake news has grown exponentially. According to a recent report, the Government of India has formulated a New Information and Technology 
Rules $2021{ }^{8}$ to regulate the content sharing on social media platforms. This has received criticism from various experts and common people alike that this will lead to a disintegration of social media platforms and thus the Government should refrain from regulating the platforms; or else this move will be indicated as a clear violation of freedom of speech and expression. Although the country is facing a series of problems due to the sudden creation and spread of uncontrollable fake news which may upset the administrative machinery of the State.

With over 680 million active internet users ${ }^{9}$ the digital population in India is growing rapidly which shows a marked change in the way the people are embracing technology. On the outside technology has become a part of everyday communication for the general population but on a deeper introspection it can be found that the real picture is different from its essence. Since internet data packs are now cheaper and internet is more accessible through smartphones, a major portion of the population are approving of the digital lifestyle. With internet being mobile friendly, the use of social media is subsequently high in India. Facebook, YouTube and WhatsApp were the most popular social networking sites having the maximum users. A noticeable point is that the onset of digital India was marked by the social media sites transcending the socio-economic boundaries as the rural areas were reported to have an increasing number of WhatsApp user; although the higher statistics of internet users stands at a contradiction to its impact on the socio-political structure. The issue of low literacy rates makes the users vulnerable to fake news and sectarian propaganda which threatens the very essence of technology, which is to propagate unbiased message. An overwhelming majority of users in the country now access social media for any news and information where information are rarely checked whether they are authentic or valid. Reportedly with around such a large number of users in India, it is the place where the maximum contents get forwarded and shared. This leads to a surge in sharing of misinformation as people tend to believe in the platform and the naïve view that it produces true and reliable information. This rising believability in information shared across these platforms is reported to lead to increase in fake news and cybercrime. Existing literature on fake news focus on the information environment being characterized by misinformation and hate, socio-cultural conflict, a digital divide and an eventually

\footnotetext{
${ }^{8}$ The Information Technology (Intermediary Guidelines and Digital Media Ethics Code) Rules, 2021. https://www.meity.gov.in/writereaddata/files/Intermediary_Guidelines_and_Digital_Media_Ethics_Code_Rules2021.pdf

${ }^{9}$ https://www.statista.com/topics/5113/social-media-usage-in-india/
} 
division among the communities. A phenomenological intervention of fake news will reveal not only what they do, but also what they say and mean. It interprets how technology appears to be in modern parlance- linked to the broader perspective of knowledge and truth, power and desire or in a nutshell, to a whole social field. While it is known that propaganda and false news are age-old tactics exploited by those in power over the subjects, digital technology magnify them with its low cost and high speed of communication which naturally increases the threat.

\section{Fake news and belief system}

There is an emerging and burgeoning literature as to why people believe and share fake news and misleading information online (Greifeneder, 2021). Social media platforms like Facebook, WhatsApp and Twitter have lately been criticized for boosting up the spread of fake news in the wake of the pandemic. What remains less discussed here is the number of people sharing them, and the reasons behind it. Majority of these literatures go by the common narratives that a certain political ideology leads individual to fake news, although in reality people are able to differentiate between truth and falsehood when they are reading a particular piece of information online. Reason for sharing fake news has been attributed to poor skills of discerning the truth which is again correlated with lack of reasoning and relevant knowledge. Covid-19 witnessed the social media platforms being inundated with deluge of information on a recurring basis. Social media were overwhelmed with doctored videos, suspicious documentaries and fake interviews related to pandemic in the wake of the crisis in the country. The burgeoning information posed a threat to people's reasoning from dissociating the truth from the falsities, Moreover, there is the issue of inattention besides intentionally sharing misinformation. Articles which are 'clickbait' ${ }^{10}$ with catchy headlines attract most numbers of users who aren't bothered to check the whole content. This often leads to a disconnection between what people actually believe and what they have shared on the media platforms. Added to this, familiar people sharing information online is another tactics to spread fake news. Social media algorithms work through all the mentioned ways to enable users to share misinformation online. A recent study which delved into this division between accuracy in judgments and intention to sharing fake news saw that people prefer political identity and a common ideology over truth and this leads to them sharing false information on

\footnotetext{
${ }^{10}$ Internet contents whose main intention is to attract visitors on the web page by inviting them to click on a link on a webpage.
} 
social media although they are aware that they may not be true. Sharing of misinformation has thus often been linked to promote one's political agenda and with the hidden intention to build chaos. Although these observations are still lacking in explaining the huge amount of information being shared online; it cannot be concluded that everyone share it with an ideological mind-set. One possibility is people have a tendency to believe social media platforms more than the news contents. This has consequence in the fact that any consumption of fake news have been damaging for the current population dependent on social media for information. Moreover, a lack of sense of reasoning which is often been attributed to this behaviour of sharing information without verification. Often this reasoning is motivated by stereotypes and ideological alignment; thus any piece of information which uphold one's belief system finds maximum share even if they are not fake. Issues such as the alleged racism against marginalized and minority communities who have been at the receiving end of stereotypes in India's socio-political scenario are one of the recent examples of the lack of rationality displayed through the spread of fake news. Doctored images of their food habits, gatherings and misinterpreted information were heavily shared over various platforms during this period. Added to this factor, method of heuristics or using mental shortcuts (Pennycook, 2021) is a strategy applied by the users while judging a particular piece of information. A familiarity spotted in a news which matches with the earlier exposure to a piece of truth is one of the heuristic process applied while judging and forwarding any information. This feeling of similarity in information and judgments of truth are conditioned by one's socialization process. Another important cue in this process relates to the source from which the information is being received. People are more likely to trust the information if they originate from the sources one finds credible and reliable. Social science literature has shown time and again that information emanating from political elites to a close acquaintance has a higher probability of impacting fake news circulations. Social media platforms provides feedback, such as likes or sharing of information and engagements under the post also boots up belief in any facts, even if some of them are fabricated. This is also a common factor if such details and figures are posted by influential figures such as any political elites or socially relevant person. People tend to believe in the fact that if any information is generated and shared by that source, they are generally true. A debate surrounding fake news essentially hints to emotional factors which perhaps forms the most important and salient feature of this phenomenon. Fake news and misinformation finds fruition if they generate emotions like fear, rage or surprise. These accumulates to the formation of moral 
outrage which channelize sharing of such information which then results in a collective and social outburst.

The above points indicates that there is a common link between the question of trust and the social networking interface. There is a common expectation attached to social media that information shared on these platforms are necessarily true and it is this cognition which gives rise to trust. This trust is developed in an online environment owing to a successful exchange of useful information and the presence of valid sources. It accelerates the risk taking behaviour among users who engage in sharing information in higher momentum. Individual has the tendency to trust the one sharing the information rather than checking the facts themselves. A high level of trust in online platforms is likely to share the information further across social media sites. The non-availability of information regarding the coronavirus has led to this gestures among users to look forward to trustable sources for information and this has in turn lessened the probability of cross-checking the evidences beforehand before sharing.

Another factor encountered during the times of crisis is the ideologies of the internet (Fuchs, 2018) Ideologies of the internet allows for a fetish of control of digital communication which is an example of neoliberalism where certain groups of people are censored and shown in different lights (Herman, 2010). The misinformation that followed the spread of the virus throws lights to the fact that this ideological tendency on the social media create an impression of a universal danger and then calls for a quick fix of the problem. While doing so a certain individual or community or a bigger whole are projected to be the source of danger and calls for monitoring and isolating them which allows the censorship and surveillance technology to function which will guarantee profit for the one who is actually in control of the information as well as the platform. This is enhanced further by a lack of media literacy on the part of the population who have more faith in the technology and the form of the news received through them. Therefore it is easier to instill this categorical suspicion in the psyche of the common mass who unconsciously support these discriminations and as a result this kind of scapegoating technology works which turns any subject from an innocent being to a body of wrong and guilt. As a result, automatically a certain number of humans become suspects and perpetrators, the range of which is wide and diverse.

\section{Fake News and the Possibility of a Post-Truth Society}


One of the challenges posed by the issue of fake news is regarding the question of truth. In March 2020, the inventor of the World Wide Web, Sir Tim Burners Lee ${ }^{11}$ stated that "misinformation, or fake news, which is surprising, shocking, or designed to appeal to our biases can spread like wildfire", and by this he called for a curbing on fake news. This naturally directs to the fact that we are already standing at the threshold of a post-truth era where the concept of truth is not a transcendental or pure entity but simply a concept in contradiction to the falsity (Urban, 1944). With the arrival of multiple information outlets, what is true actually loses significance as every facts needs authentication and validation. This is where truth becomes powerless and falsity gains momentum. Alternative facts and emergence of post truth throws light on the issue that people instead of searching for what is necessary and real would rather search for what aligns with their perception. This is also reflected in the general pattern of interaction online, as people on media platforms like Facebook or Twitter would generally align themselves with those who possess similar views as them.

Media scholars and experts consent to the fact that it is not the authorities who are in charge of handling what is true and what is not, but it is now networked by users online. As a result what is witnessed is huge number of facts online which is followed by similar or large numbers of counterfacts. The dilemma is often those facts and their counter look undistinguishable to the point that a user reading them is unable to discern which one is true. This 'farcical claims' (Ball, 2017) is a part of the emerging economy concerned with alternative facts which creates an ecosystem of misinformation for thriving. Therefore fake news as category of the emerging environment of alternate facts is not an exclusive or disjointed phenomenon; rather they have a political-economic dimension to it. Resultantly what is witnessed is truth now being considered as relative and absolute facts being manipulated by a new breed of knowledge producers who tweak truths for their own benefit. Likewise, this phenomenon is followed by a formation of polarised views in society which helps in fuelling and supporting propaganda and 'conspiracy theories'. Much alike information which is regarded as a social process, misinformation and fake news is also considered as a social condition, a reality in the present digital era. A common technique which the fake news industry have adopted is to take images and voices out of their original contexts thus distorting the truth associated with them. Rather it gives birth to a new kind of truth or a post-truth which carries

\footnotetext{
${ }^{11}$ See https://webfoundation.org/2020/03/web-birthday-31/
} 
a negative connotation in itself. They are considered to be verified facts until and unless another set of news arrives to prove their falsity and this chain continues to give birth to innumerable number of stories inundating the digital platforms- a characteristic quite common to post modernism which completely deny any presence of absolute truth in the contemporary world. This precedes the fact that technological advancements have made the mainstream media weak in providing fast information, digital platforms have made public interaction and communication fluid on the contrary and this rush to provide fast information have often resulted in tampering with the definition of truth.

The sudden surge of fake news following the covid 19 pandemic has provided an instrumentalist conception of post truth where there is a tendency to re-assert what is the actual fact, accompanied by the rise of fact-checking. It needs to be mentioned here that post-truth is not a recent phenomenon. If one gives a cursory glance to history, one can see the existence of propaganda and disinformation since historical times, in the forms of myths, folklores, and fictional story telling. False stories, states historian Yuval Noah Harari ${ }^{12}$ is advantageous to truth when it comes to uniting people. ${ }^{13}$ In the contemporary world absurdities and misinformation is easier to spread and act as catalyst to unify people thus checking group loyalty. Reiterating the same fact it needs to be said again, rather than truth, false information cater to the stereotype belief of the masses and with social media, it is easier to feed the common people with these information. In a country like India, where there is a huge presence of political and social polarization and differences in thought and speech, fake news further promotes a simulated worldview which distorts reality thus furthering the already existing discriminations. This prohibits the society from realizing the actual truth.

While it can be said that fake news in contemporary times are the modern rendition of traditional conspiracy theories channelized through majorly social media, it is transformed into a tool in the hands of power mongers to systematically attack and undermine a particular group within and outside the country. The current political trend in the country after the virus outbreak are visibly shaped by misleading information regarding minority and marginalized group's culture and habits and linking them to spreading the virus without any verification, or the stigma attached to people

\footnotetext{
${ }^{12}$ Harari, Y. N. (2020). The world after coronavirus. Financial Times, 20(03), 2020. See https://www.envio.org.ni/articulo/5772
} 
returning from abroad without any solid claims that the virus is being spread by them in the country. What followed was numerous political debates both online and offline which were centred on these unverified information that went viral due to large numbers of sharing. Therefore the current discussion regarding society and politics has been slowly shifting from factual accuracy to a 'post-truth' ground where truth is abandoned.

\section{Conclusion}

Thus, what is seen so far is how fake news pose a challenge to the socio-political fabric of a country. The internet and social media platforms are part of the newly emerged digital social systems, therefore fake news should be analyzed in the context of socio-political and cultural dimensions of a country. The economy, politics and culture in India which is already characterized by caste and ethnicity based discrimination and stratification is further enhanced through these alternate facts which functions through spreading propaganda, hate speech and fake news as clickbait for profit. This in turn gives birth to ideology which influences the perceptions of the user. Fake news has a wider social connotation, as it is not to be reflected as something emerging all of a sudden. In contrast, fake news has long been associated with the idea of governance and politics which comes into view when truth enters into a crisis. It can be considered to having power in a limited time frame where it acts as a source of truth by overshadowing what in fact consists of truth.

\section{References}

Ball, J. (2017). Post-truth: How bullshit conquered the world. Biteback Publishing.

Bharali, B. \&. (2010). Fake news: Credibility, cultivation syndrome and the new age media. Media Watch, 118-130.

Fondren, E. (2019). Fake News, Propaganda, And Plain Old Lies: How to Find Trustworthy Information in the Digital Age. Taylor and Francis.

Greifeneder, R. J. (2021). The Psychology of Fake News: Accepting, Correcting and Sharing Misinformation. New York: Routledge. 
Herman, E. S. (2010). Manufacturing consent: The political economy of the mass media. . Random House.

Pennycook, G. \&. (2021). The psychology of fake news. Trends in cognitive sciences.

Posetti, J. \&. (2017). A short guide to the history of' fake news' and disinformation. . International Center for Journalists, 1-19.

Sharma, P. \&. (2020). Indian media coverage of Nizamuddin Markaz event during COVID-19 pandemic. Asian Politics and Policy.

Shirky, C. (2011). The political power of social media: Technology, the public sphere, and political change. Foreign Affairs, 28-41.

Urban, W. (1944). The dialectic of meaning and truth: truth as immanent in discourse. . Philosophy and Phenomenological Research, 377-400. 